\title{
Pilot Study of Isoniazid Acetylation in Melanesian Healthy Subject from Indonesia
}

\author{
Novi Yantih', Yahdiana Harahap ${ }^{2, *}$, Rianto Setiabudy³, Wahono Sumaryono ${ }^{1}$ \\ 'Pharmacy Faculty, Universitas Pancasila, Jakarta, INDONESIA. \\ 2Faculty of Pharmacy, Universitas Indonesia, Depok, West Java, INDONESIA. \\ ${ }^{3}$ Medical Faculty, Universitas Indonesia, Jakarta, INDONESIA.
}

\begin{abstract}
Objective: Isoniazid (INH) is metabolized by $\mathrm{N}$-acetyl transferase-2 into acetyl isoniazid (Ac-INH). The acetylation rate is different in each ethnic, therefore it is very interesting to study of INH acetylation. The aims of this study were to synthesize $\mathrm{Ac}-\mathrm{INH}$ and the produced $\mathrm{Ac}-\mathrm{INH}$ was used as a working standard for the pilot study of INH acetylation in Melanesian healthy subjects from Indonesia. Methods: Ac-INH can be simply synthesized by acetylation reactions between INH and acetic anhydride. The synthesis results were characterized by organoleptic observation, purity test, UV-Vis spectrophotometry analysis, FTIR analysis, and mass spectrometry analysis. The pilot study of INH acetylation used high performance liquid chromatography to analyze the levels of INH and Ac-INH in blood of Melanesian healthy subjects. The acetylation rate of INH was determined by the ratio between $\mathrm{Ac}-\mathrm{INH}$ and INH concentrations at $3 \mathrm{~h}$ after administration of INH. Results: The acetylation reaction to synthesize Ac-INH has been performed at temperature of $60^{\circ} \mathrm{C}$ for $30 \mathrm{~min}$. The obtained Ac-INH had the same quality specifications with reference standard of $\mathrm{Ac-INH}$.
\end{abstract}

The average of ratio between of $\mathrm{Ac}-\mathrm{INH}$ and INH concentrations was $<1.5$. The results showed that the six healthy subjects of Melanesians had slow acetylation. There was significant difference in the ratio between $\mathrm{Ac}-\mathrm{INH}$ and INH concentrations in subjects $(P<0.05)$. Conclusion: The obtained Ac-INH could be used for pilot study of INH acetylation by calculating the ratio of Ac-INH and INH concentrations in plasma subject. The subject has to be increased to represent the Melanesian population from Indonesia.

Key words: Isoniazid, Acetyl isoniazid, Acetylation rate, Melanesia.

Correspondence

Yahdiana Harahap, Faculty of Pharmacy, Universitas Indonesia, Depok, West Java, INDONESIA.

Phone: +62 (21) 78849001

Email: novi_yantih@yahoo.com; icapps2017.farmasiui@gmail.com

DOI: 10.5530/jyp.2018.2s.29

\section{INTRODUCTION}

Tuberculosis (TB) remains one of the deadliest infectious diseases in the world, so that it becomes a priority for world health. ${ }^{1} \mathrm{~TB}$ is an infectious disease caused by Mycobacterium tuberculosis, which commonly affects the lungs. Isoniazid (INH) is the first line therapy for TB treatment, either as a single drug or in combination..$^{2-3} \mathrm{INH}$ treatment successes is related to its bioavailability in blood, therefore, it is necessary to study the pharmacokinetics of the drug in the blood monitoring. ${ }^{4-6}$

Isoniazid (INH) in the body undergoes major metabolism by $\mathrm{N}$-acetyltrasferase- 2 enzyme converted into acetyl isoniazid (Ac-INH). ${ }^{7}$ Acetylation rate may differ in individuals depending on $\mathrm{N}$-acetyltransferase- 2 (NAT-2) activity. In general, the phenotype of acetylation due to genetic polymorphism can be divided into two major groups of slow acetylation phenotype and rapid acetylation phenotype. ${ }^{8}$

In support of metabolism studies of INH in human, it is necessary to produce Ac-INH. The aim of this study was to synthesize Ac-INH in which the synthesis result was applied as working standard to study INH acetylation in healthy subjects. Ac-INH is required as a reference standard in pharmacokinetic studies of INH. Ac-INH can be synthesized from INH by way of acetylation. Acetylation reaction involves the transfer of an acetyl group catalyzed by the NAT- 2 in human body, while chemical synthesis can be performed by conducting reactions between INH and acetic anhydride. ${ }^{9-10}$

In this research, Ac-INH was synthesized through acetylation reaction by reacting with acetic anhydride and INH at different temperature and heating time. The optimization of the heating temperature and length of time were needed to produce optimal Ac-INH. The synthesis results were characterized by organoleptic observation, determination of the melting point range, UV-Vis spectrophotometry analysis, FTIR analysis, and mass spectrometry analysis. The produced Ac-INH was used as working standard of Ac-INH for the study of INH acetylation in Melanesian healthy subjects from Indonesia. The selection of subjects from Melanesian ethnicity in Indonesia because research on the rate of their acetylation has not been reported. INH and Ac-INH concentrations in the blood were analyzed by using high performance liquid chromatography (HPLC) to determine acetylation rate of INH.

\section{MATERIALS AND METHODS}

\section{Chemicals and reagents}

INH (Zhejiang Jiangbei Pharmaceutical, Zhejiang, China), acetic anhydride, ether and ethanol (Merck, Darmstadt, Germany) were pro analysis grade. Ac-INH standard was from Santa Cruz Biotecnology, Inc, Texas (USA).

\section{Synthesis of Ac-INH and its characterization}

Raw materials of INH and Ac-INH were identified by organoleptic observation and analyzed by using FTIR (Shimadzu 8400S, Kyoto, Japan). The purity test of both materials was conducted by determining the loss on drying and the melting point (Buchi B-540, Missouri, USA). The temperature optimization was conducted by reacting INH and acetic anhydride over a water bath (Julabo TW20, Allentown, USA) at a temperature of $30,40,50,60,70$ and $80^{\circ} \mathrm{C}$ with prolonged heating for $30 \mathrm{~min}$. While the length of time of the reaction was determined at a 
temperature of $60^{\circ} \mathrm{C}$ with the standing for $15,30,45,60$ and $90 \mathrm{~min}$. The reaction was conducted under anhydrous conditions. Purification was conducted by dissolving the synthesis results in a row in ethanol, ether, and ethanol. The synthesis were dried and stored at $-20^{\circ} \mathrm{C}$. The purity of synthesized compound was determined by the range of melting. The synthesis result was characterized by UV-Vis spectrophotometry (Shimadzu 1800, Kyoto, Japan) to obtain the absorption spectrum and the wavelength of maximum absorption. FTIR was used to characterize the functional group of the synthesis result to be compared with functional groups of INH and reference standards Ac-INH. While mass spectrometry (MS TQD Aquity, Milford Massachusetts, USA) was used to determine the molecular weight of compounds synthesized.

\section{Subjects}

This study has passed the ethical approval from Medical Research Ethics Commission of the Faculty of Medicine Universitas Indonesia-Cipto Mangunkusumo Hospital (No:420/UN2.F1/ETIK/IV/2017). Participating subjects are aged between 18-40 years, with a body mass index of $18-28 \mathrm{~kg} / \mathrm{m} 2$. Prior to the study, each subject had been given detailed explanation of the objectives, protocols and risks that may occur from this study. Each subject had signed informed consent. All subjects were in good health and history of a good medical record. The subject's health conditions were determined based on the results of physical health checks by physicians and routine blood tests in clinical laboratories. All subjects must meet inclusion criteria and not allowed to take medication 2 weeks before the study and during the study, and should avoid severe physical activity. Subjects were not allowed to consume foods containing alcohol, tea and coffee for 2 days into the study period.

Before the drug was given, the subject should fast at least $8 \mathrm{~h} .{ }^{11}$ Water allowed to be consumed was limited to $400 \mathrm{~mL}$ during fasting, except $1 \mathrm{~h}$ before and $2 \mathrm{~h}$ after administration of INH. The total calories of food allowed were $800 \mathrm{kcal}$. The health evaluation of the subject's health by physician was performed before, during, and after treatment. Human plasma was collected at $3 \mathrm{~h}$ after administration of INH. The levels of INH acetylation in healthy subjects were evaluated based on the ratio of Ac-INH and INH levels. Analysis of Ac-INH and INH levels were done by HPLC (Shimadzu LC 20 AD, Kyoto, Japan).

\section{HPLC system for analysis INH and Ac-INH in metabolism studying of $\mathrm{INH}$}

The HPLC system was completed with C18 (150mm x $4.6 \mathrm{~mm})$ as stationary phase, hexane sulphonate $20 \mathrm{mM}$ (pH 2.47)-methanol (65:35) as mobile phase, with flow rate of $1 \mathrm{~mL} / \mathrm{min}$, UV detector at wavelength of $265 \mathrm{~nm}$, and vitamin B6 (Vit-B6) as an internal standard. This method has been validated according to Guidance for Industry Bioanalytical Method of Validation. ${ }^{12}$

\section{RESULTS}

\section{Synthesis of Ac-INH and its characterization}

Synthesis was carried out on a long reaction time i.e. 15, 30, 45, 60, and $90 \mathrm{~min}$ by heating in a water bath at $60^{\circ} \mathrm{C}$. The yields were observed with variation of heating temperature i.e. $30,40,50,60,70$, and $80^{\circ} \mathrm{C}$ within $30 \mathrm{~min}$. The optimization results showed the optimum acetylation reaction condition to synthesize Ac-INH from INH and acetic anhydride was at temperature $60^{\circ} \mathrm{C}$ for $30 \mathrm{~min}$ (Figure 1 and 2).

Conducted characterization of Ac-INH consisted of organoleptic observation, melting range observation, spectral transmittance analysis, absorption spectra analysis and molecular weight determination. Based on the results of characterization, the obtained Ac-INH had the same quality specifications with Ac-INH standard (Table 1).
Figure 3 and Table 1-2 showed that spectral transmittance profile of the obtained Ac-INH was equal to the transmittance spectra of Ac-INH standards, but both spectra showed different profiles of INH spectrum (Figure 4). N-H peak of hydrazine group on Ac-INH spectrum was not appeared at the wavenumber $1139.85 \mathrm{~cm}^{-1}$ (Table 2). The acetyl group peak was described at $3448.49 \mathrm{~cm}^{-1}$ in Figure 3.

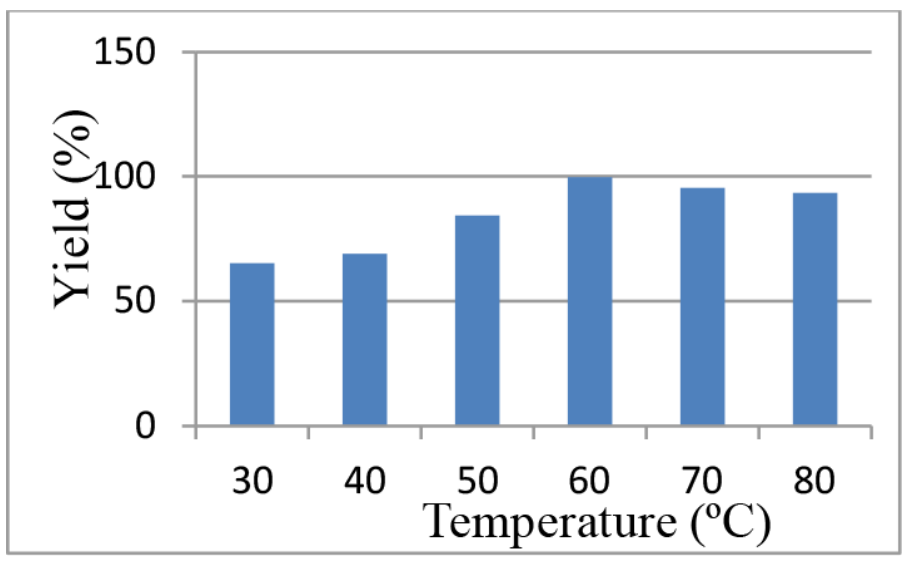

Figure 1: Yield of acetyl isoniazid (\%) at various temperature variations in 30 min of heating.

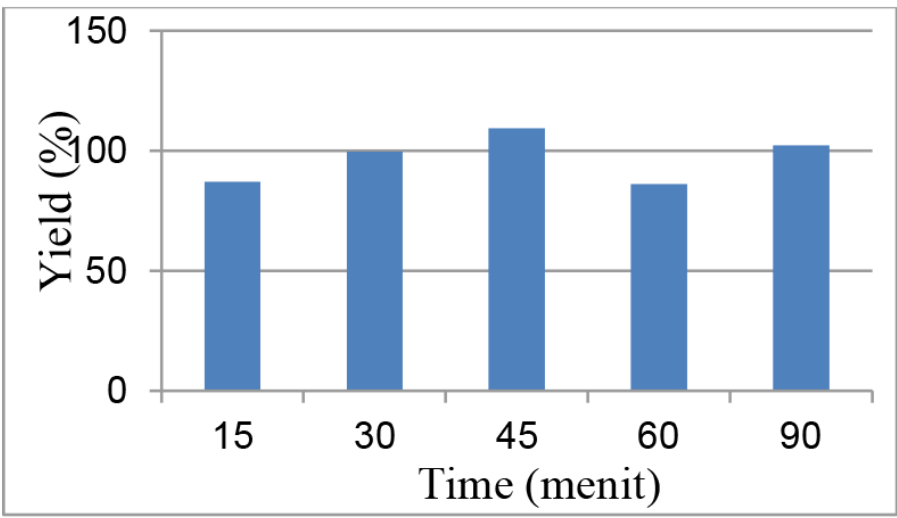

Figure 2: Yield of acetyl isoniazid (\%) at the various time on heating of $60^{\circ} \mathrm{C}$.

Table 1: Characteristics of acetyl isoniazid synthesis result based on the specifications of the organoleptic, melting point, transmittance spectrum, wavelength, molecular weight and purity.

\begin{tabular}{|c|c|c|c|}
\hline \multirow{2}{*}{ No } & \multirow{2}{*}{ Parameters } & \multicolumn{2}{|c|}{ Acetyl Isoniazid } \\
\hline & & Reference $^{13}$ & Synthesis results \\
\hline \multirow[t]{5}{*}{1} & Organoleptic: & & \\
\hline & a. Form & Crystalline powder & Pass \\
\hline & b. Color & White to yellowish & Pass \\
\hline & c. Odor & white & Pass \\
\hline & & Odorless & \\
\hline 2 & Melting point $\left({ }^{\circ} \mathrm{C}\right)$ & $159.0-160.0$ & $157.2-160.3$ \\
\hline 3 & $\begin{array}{l}\text { Transmittance } \\
\text { spectrum }\end{array}$ & Finger print profile & Pass \\
\hline 4 & Wavelength $/ \lambda_{\max }(\mathrm{nm})$ & 265.50 & 265.50 \\
\hline 5 & Molecular weight & 180.4 & $\begin{array}{c}180.05 \text { (mass } \\
\text { spectrum) }\end{array}$ \\
\hline 6 & Purity (\%) & 98 & $\begin{array}{c}95.38 \text { (UV } \\
\text { spectrophotometry) }\end{array}$ \\
\hline
\end{tabular}


Table 2: Wavenumber of acetyl isoniazid (Ac-INH) reference standard and synthesis result using FTIR.

\begin{tabular}{|c|c|c|c|c|}
\hline \multirow[b]{2}{*}{ No } & \multirow[b]{2}{*}{$\begin{array}{c}\text { Functional } \\
\text { Groups }\end{array}$} & \multicolumn{3}{|c|}{ Wavenumber $\left(\mathrm{cm}^{-1}\right)$} \\
\hline & & Reference ${ }^{14}$ & $\begin{array}{c}\text { Ac-INH } \\
\text { Reference } \\
\text { Standard }\end{array}$ & $\begin{array}{c}\text { Ac-INH } \\
\text { Synthesized }\end{array}$ \\
\hline 1 & $\mathrm{~N}-\mathrm{H}$ & $3140-3320$ & 3240.19 & 3232.47 \\
\hline 2 & RCONH & $3125-3570$ & 3448.49 & 3448.49 \\
\hline 3 & Pyridin & 1555.5 & 1554 & 1554 \\
\hline 4 & $\mathrm{C}=\mathrm{O}$ amide & $1630-1690$ & 1652.88 & 1687.6 \\
\hline 5 & $\mathrm{C}=\mathrm{C}$ & $1500-1600$ & $\begin{array}{l}1550.66 \\
1517.66\end{array}$ & $\begin{array}{l}1552.59 \\
1517.87\end{array}$ \\
\hline 6 & $\begin{array}{c}\text { C-H aromatic } \\
\text { substitution }\end{array}$ & $\begin{array}{c}\text { 3010-3095 } \\
\text { (medium) } \\
900-600 \text { (strong) }\end{array}$ & $\begin{array}{c}3029.96 \\
896.84 ; 850.55 \\
752.19\end{array}$ & $\begin{array}{c}3029.96 \\
896.84 \\
850.55 ; 752.29 \\
700.11\end{array}$ \\
\hline
\end{tabular}

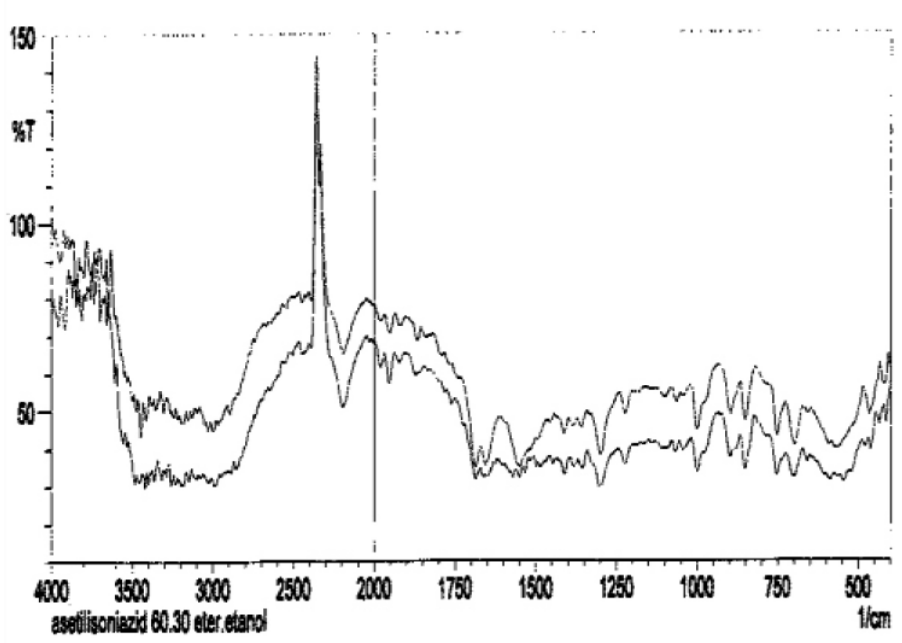

Figure 3: Overlay FTIR spectrum of acetyl isoniazid standard (upper spectrum) and synthesized (sub-spectrum).

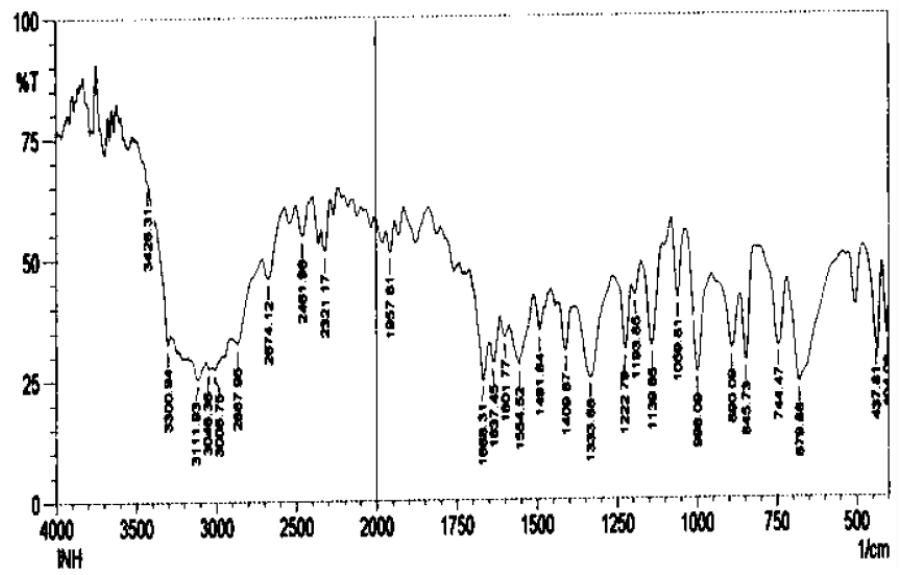

Figure 4: FTIR spectrum of isoniazid.
The absorption spectra of standard Ac-INH can be seen in Figure 5. The figures showed that the maximum absorption wavelength of synthesized compound $\left(\lambda_{\max }\right)$ was equal to the Ac-INH reference standard.

The molecular weight of the obtained Ac-INH was conducted. The mass spectrometer was fired at a substance with an electron beam and then record the spectrum which is a positive ion fragments $(m+1)$ are separated by mass. Fragmentation of Ac-INH was seen at $\mathrm{m} / \mathrm{z} 180.4,138.1$, and 120.02. The molecular weight measured by using mass spectrum, showed the molecular weight of the fragment was 180.05 (95\%). This result is close to Ac-INH mass spectrum data generated from ChemOffice program, ${ }^{15}$ which was 180.4 (Table 1 ).

\section{Application the Synthesized of Ac-INH in Pilot Studying of INH acetylation}

For pilot studying of INH acetylation, the ratio of Ac-INH and INH concentrations in subject's plasma were calculated to determine the acetylation rate of INH. The concentrations of Ac-INH and INH were analyzed by using HPLC. Figure 6 described the chromatogram of Ac-INH and INH in human plasma. The obtained resolution of INH-Ac-INH and Ac-INH-Vit-B6 were 1.508 and 1.923, respectively. The tailing

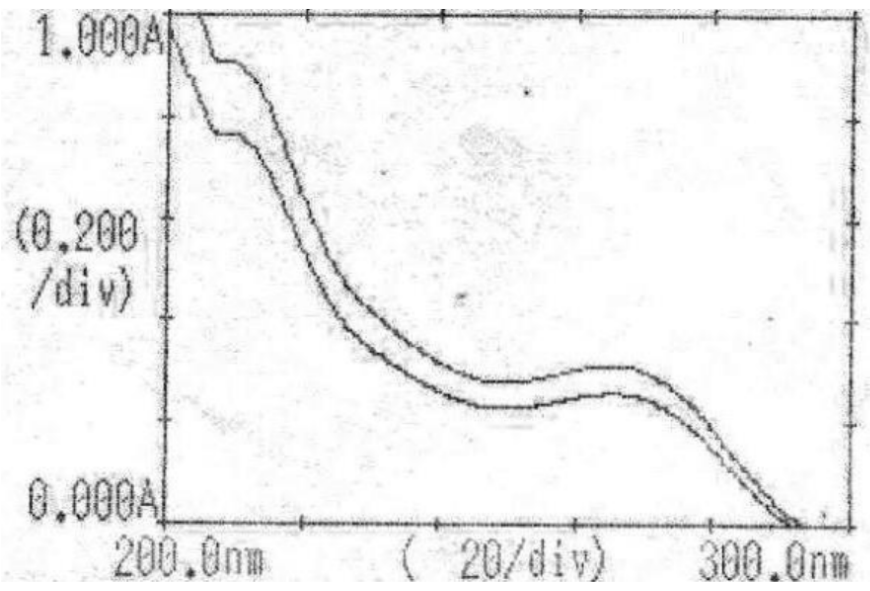

Figure 5: Overlay Absorption spectra of acetyl isoniazid standard (upper spectrum) and synthesized (sub-spectrum).

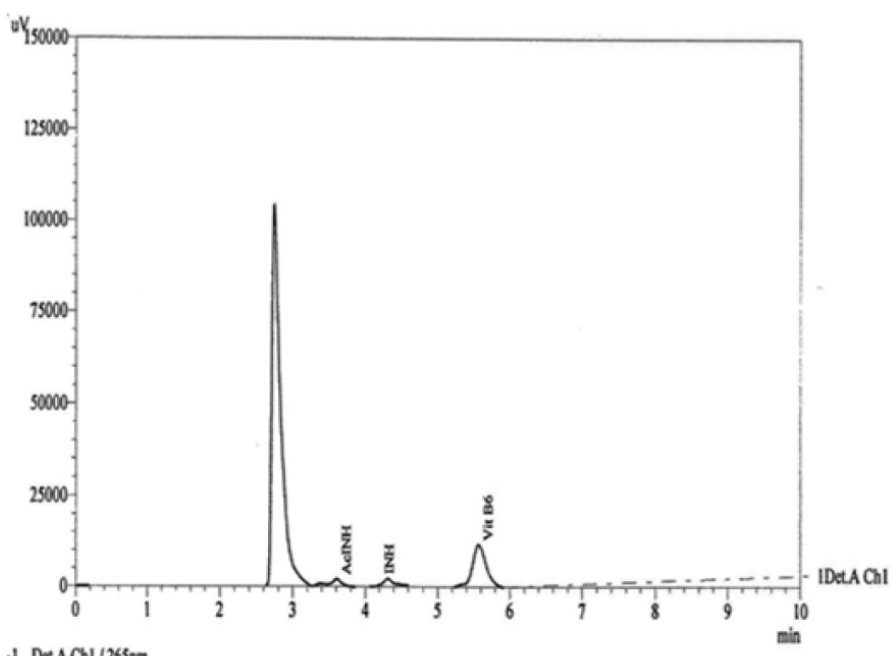

1) DeeAChl/265m

Figure 6: Chromatogram of acetyl isoniazid (Ac-INH) and isoniazid (INH) in human plasma sample with vitamin B6 (Vit-B6) as internal standard. 
Table 3: Results of the least significant difference tests for ratio of acetyl isoniazid and isoniazid concentrations of six healthy subjects from Indonesia.

\begin{tabular}{ccccc}
\hline & & \multicolumn{2}{c}{ Ratio of Acetyl Isoniazid and Isoniazid Concentrations } \\
\cline { 3 - 5 } Subject & $\mathrm{N}$ & Mean & $\begin{array}{c}\text { Standard } \\
\text { Deviation }\end{array}$ & $\begin{array}{c}\text { Coefficient of } \\
\text { Variance (\%) }\end{array}$ \\
\hline 1 & 3 & $0.93^{\mathrm{c}}$ & 0.022 & 2.37 \\
2 & 3 & $1.20^{\mathrm{d}}$ & 0.064 & 5.29 \\
3 & 3 & $0.53^{\mathrm{b}}$ & 0.006 & 1.14 \\
4 & 3 & $0.91^{\mathrm{c}}$ & 0.065 & 7.14 \\
5 & 3 & $0.12^{\mathrm{a}}$ & 0.006 & 5.21 \\
6 & 3 & $0.15^{\mathrm{a}}$ & 0.007 & 4.45 \\
\hline
\end{tabular}

Data followed by different letters within each column are significantly different at $\mathrm{P}=6.391 \times 10-13(<0.05)$.

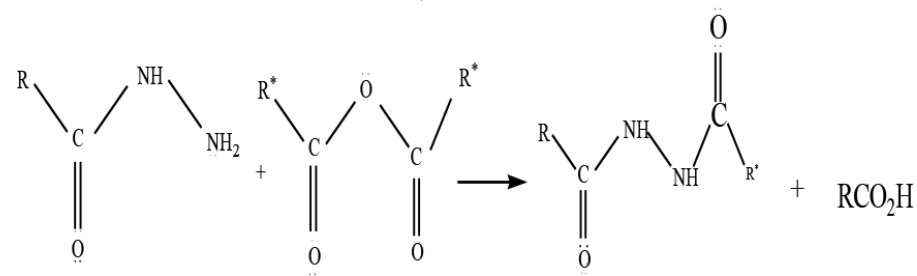

Figure 7: The acetylation reaction with acid anhydride. ${ }^{16}$

factor of INH, Ac-INH, and Vit-B6 were 1.160, 1.101, and 0.911 respectively. The $\mathrm{k}$ values were less than 10 and $\mathrm{N}$ values were greater than 5000 .

The acetylation rate in six healthy subjects from Indonesia were slow acetylation with an average ratio of Ac-INH to INH $<1.5$ (Table 3). Statistical analysis showed that there was significant difference in the ratio between Ac-INH and INH concentrations in six healthy subjects $(P<0.05)$.

\section{DISCUSSION}

Ac-INH is a compound synthesized enzymatically from INH by the acetylation reaction supported by NAT-2. Acetylation reaction in the synthesis of Ac-INH is a convenient reaction that able to occur slowly at room temperature (Figure 7). The acetylation reaction is accelerated by heating. In this study, the compound was synthesized from INH raw materials. INH was acetylated with acetic anhydride by heating process. The heating process was conducted to accelerate the formation reaction of Ac-INH. The heating process by using water bath method was selected because it is the most convenient method to aid in the synthesis. Temperature and length of heating time have been optimized to produce the highest yield of Ac-INH.

The obtained Ac-INH was characterized to determine the quality of the obtained Ac-INH to be confirmed to the reference standard. ${ }^{13}$ Based on the results of characterization, the obtained Ac-INH had the same quality specifications with Ac-INH standard (Table 1 and 2). Thus, it can be concluded that INH reaction and acetic anhydride at $60^{\circ} \mathrm{C}$ for $30 \mathrm{~min}$ is able to produce new compound, namely Ac-INH (Figure 1 and 2). These results were confirmed by analyzing the spectral transmittance, absorption spectra, and the mass spectrum of the obtained Ac-INH synthesis results. This showed that hydrazide group had been substituted by acetyl group (Figure 3 and 4). The infrared spectrum of INH which was prepared in potassium bromide $\mathrm{P}$ showed the $\mathrm{N}-\mathrm{H}$ peak of the hydrazine group at the $1139.85 \mathrm{~cm}-1$ (Figure 4), whereas in the Ac-INH spectrum was prepared in the same manner was not showed the hydrazine peak at the same wavenumber (Figure 3). However, the peak of the acetyl group was appeared on the FTIR spectra of Ac-INH in the $3448 \mathrm{~cm}^{-1}$ (Figure 3), where the peak was not appeared in the INH spectrum (Figure 4). This suggested that the acetylation reaction between INH and acetic anhydride at $60^{\circ} \mathrm{C}$ for $30 \mathrm{~min}$ in a water bath has succeeded in forming Ac-INH. The hydrazine group in INH gives a positive mesomeric effect that pushes electrons into the conjugation system of the pyridine group, so that hydrogen in hydrazine becomes easily removed and substituted by acetyl groups. ${ }^{17}$ The obtained Ac-INH had the same quality specifications with reference standard of Ac-INH (Table 2, Figure 3 and 5) and was used as working standard in pilot study of INH acetylation.

Acetylation rate may differ in individuals depending on $\mathrm{N}$-acetyltransferase-2 (NAT-2) activity. In general, the phenotype of acetylation due to genetic polymorphism can be divided into two major groups of slow acetylation phenotype and rapid acetylation phenotype. ${ }^{8}$ The acetylation rate of INH was determined based on ratio of Ac-INH and INH concentrations in subject's plasma which was sampled three hours after administration of INH. ${ }^{7}$ This study involves a healthy subject because the status of tuberculosis disease is known not to affect the rate of acetylation of INH. ${ }^{18}$

HPLC is a selective and sensitive method for determination of Ac-INH and INH concentrations in plasma. Based on the resolution, tailing factor, $\mathrm{k}$ values, and $\mathrm{N}$ values indicated good separation efficiency by HPLC system for determining of Ac-INH and INH in human plasma (Figure 6). The ratio of Ac-INH and INH concentrations on each subjects showed a good precision with coefficient of variance was less than $15 \%{ }^{12}$ The results showed that acetylation rate in six healthy subjects from Indonesia were slow acetylation. Ethnic Melanesians in Indonesia belong to the Negroid race group. ${ }^{19}$ The Negroid race has been reported to have slow acetylation characteristics, ${ }^{20}$ so that Melanesians from Indonesia may also have similar characteristics.

One-way analysis of variance test was used to compare ratio of Ac-INH and INH concentrations, and least significance difference Ronald Fisher's test was performed for determining different subject. Non-homogeneous data of ratio of Ac-INH and INH concentrations indicated that the number of subject has to be increased to describe a Melanesian population in Indonesia for INH acetylation study.

\section{CONCLUSION}

Ac-INH compounds could be synthesized by heating using a water bath at $60^{\circ} \mathrm{C}$ for $30 \mathrm{~min}$. The obtained of Ac-INH could be used for pilot study of INH acetylation by calculating the ratio of Ac-INH and INH levels in plasma subject. The six subject of Melanesian from Indonesia were slow acetylation. For studying of acetylation rate of Melanesian, the subject has to be increased to represent the Melanesian population in Indonesia.

\section{ACKNOWLEDGEMENT}

Special thanks are devoted to Ministry of Research, Technology and Higher Education of the Republic of Indonesia for founding the research.

\section{CONFLICT OF INTEREST}

The authors declare no conflict of interest.

\section{ABBREVIATIONS}

INH: Isoniazid; Ac-INH: Acetyl isoniazid; UV-Vis: Ultra Violet-Visible; P: Probability value; TB: Tuberculosis; NAT-2: N-acetyltransferase-2; FTIR: Fourier Transform Infra-Red; HPLC: High Performance Liquid Chromatography; UV: Ultra Violet; Vit-B6: Vitamin B6. 


\section{SUMMARY}

In support of metabolism studies of isoniazid (INH) in human, it is necessarywas synthesized through acetylation reaction by reacting with acetic anhydride and INH at different temperature and heating time. The optimization results showed the optimum acetylation reaction condition to synthesize Ac-INH was at temperature $60^{\circ} \mathrm{C}$ for $30 \mathrm{~min}$. The produced Ac-INH was used as working standard of Ac-INH for the study of INH acetylation in Melanesian healthy subjects from Indonesia. For pilot studying of INH acetylation, the ratio of Ac-INH and INH concentrations in subject's plasma were calculated to determine the acetylation in Melanesian. The concentrations of Ac-INH and INH were analyzed byusing HPLC. The acetylation rate in six healthy subjects from Indonesia were slow acetylation with an average ratio of Ac-INH to $\mathrm{INH}<1.5$. Statistical analysis showed that there was significant difference in the ratio between Ac-INH and INH concentrations in six healthy subjects $(\mathrm{P}<0.05)$. It indicated that the number of subject has to be increased todescribe a Melanesian population in Indonesia for acetylation studyto produce acetyl isoniazid (Ac-INH). In this research, Ac-INH

\section{REFERENCES}

1. World Health Organization. Global tuberculosis report 2014. France: world health organization. 2014

2. Indonesian Doctors Association. Guidelines for diagnosis and management of tuberculosis in Indonesia. 2006.

3. Ministry of Health. Indonesia. Minister of Health Decree No.328/Menkes/ IX/2013 on National Formulary. 2013

4. Istiantoro YH, Setiabudy R. Pharmacology and Therapy Edition V. Jakarta (Indonesia): Department of Pharmacology and Therapeutic Medical Faculty Universitas Indonesia. 2007;613-33

5. Peloquin CA. Tuberculosis. Pharmacotheraphy: a pathophysiologic approach 7th Edition. USA: McGraw-Hill. 2008.

6. Bhatt NB, Barau C, Amin A, Baudin E, Meggi B, Silva C, et al. Pharmacokinetics of rifampin, and isoniazid, in tuberculosis-HIV-coinfected patients receivingnevi- rapin, -or efavirenz-base antiretroviral treatment. Antimic Agents and Chemo. 2014;58(6):3182-90.

7. Teixeira RL, Morato RG, Cabello PH, Muniz LM, Moreira AS, Kritski AL, et al. Genetic polymorphisms of NAT2, CYP2E1 and GST enzymes and the occurrence of antituberculosis drug-induced hepatitis in brazilian TB patients. Mem Inst Oswaldo Cruz. 2011;106(6):716-24.

8. Evans DAP. N-acetyltransferase. In pharmacogenetics of drug metabolism Pergamon Press Inc. New York (USA). 1992;95-178.

9. Olson WA, Dayton PG, Israeli ZH, Pruitt AW. Chem Clin. Spectrophotofluorometric Assay for Isoniazid and Acetyl Isoniazid In Plasma Adapted to Pediatric Studies. 1977;23(4):745-8.

10. Preziosi P. Isoniazid: Metabolic, aspect and toxicological correlates. Current Drug Metab. 2007;8(8):839-51.

11. European Medicines Agency. Guideline on bioanalytical method validation. EMEA/CHMP/EWP/192217/2009. 2012.

12. Food Drug Administration. Guidance for industry bioanalytical method of validation. 2013. Available from: www.fda.gov/cder/guidance/index.htm. 2013.

13. Santa Cruz Biotechnology Inc. Certificate of Analysis Acetylisoniazid. 2015. CS ChemOffice. ChemDraw Ultra 7.0.1. Cambridge Soft Corp. 2002.

14. Babu JM, Sevukarajan M, Thamizhvanan K, Naveenkumar B, Reddy BS Vivekananda $U$, et al. Evaluation of physiochemical and anti-tubercular activity of co-crystal of isoniazid with methyl paraben, Int J Innovative Drug Discover. E ISSN 2249-7609. Print ISSN 2249-7617. 2013;3(1):10-27.

15. CS ChemOffice. ChemDraw Ultra 7.0.1. Cambridge Soft Corp. 2002.

16. Firdaus. Organic chemistry synthesis section 2. Textbook writing grants. Makassar: Faculty Mathematics and Natural Sciences Hasanuddin University. 2014:28-31.

17. Da Silva AS. Evaluation of isoniazid and rifampicin on the biophysical properties of the membrane studied with 3D model systems [Disertation]. Faculdade De Farmacia Universidade Do Porto. 2013.

18. Yuliwulandari R, Sachrowardi Q, Nishida N, Takasu M, Batubara L, Susmiarsih TP, et al. Polymorphisms of promoter and coding regions of the arylamine $\mathrm{N}$-acetyltransferase2 (NAT2) gene in the Indonesian population: Proposal for a new nomenclature. Journal of Human Genetics. 2008;53(3):2019.

19. Deda AJ, SS Mofu. Indigenous and tribal peoples in west Papua province as indigenous Papuans in terms of custom and culture; A contemporary ethnographic study. Journal of Public Administration. 2014;11(2):11-21.

20. Chauhan N, H Padh. Variants of NAT-2 polymorfisms: Intra and inter-ethnic differences. African Journal of Biotechnology. 2014;13(51):4639-46.

Article History: Submission Date : 10-01-2018 ; Revised Date : 28-01-2018; Acceptance Date : 12-03-2018.

Cite this article: Yantih N, Harahap Y, Setiabudy R, Sumaryono W. Pilot Study of Isoniazid Acetylation in Melanesian Healthy Subject from Indonesia. J Young Pharm. 2018;10(2):s140-s144. 